\title{
Dubin-Johnson syndrome presenting with neonatal cholestasis
}

\author{
Chi-Chang Shieh, Mei-Hwei Chang, Chi-Long Chen
}

\begin{abstract}
We report a case of Dubin-Johnson syndrome presenting with neonatal cholestasis. Liver histology was studied during the neonatal period and at 6 years of age. Distinct brownish pigment granules in hepatocytes were noted. This case confirms that Dubin-Johnson syndrome is a cause of neonatal cholestasis.
\end{abstract}

Dubin-Johnson syndrome is a form of benign, familial idiopathic jaundice presenting with chronic intermittent conjugated hyperbilirubinaemia. A melanin like pigment has been found in the parenchymal liver cells, ${ }^{1}$ but has seldom been recognised during infancy.

This paper describes a young boy with Dubin-Johnson syndrome characterised by prolonged cholestasis in early infancy and an accumulation of specific pigment granules in the liver cells by 6 years of age.

National Taiwan

University

College of Medicine,

Department of

Paediatrics

Chi-Chang Shieh

Mei-Hwei Chang

Department of Pathology

Chi-Long Chen

Correspondence to:

Dr Mei-Hwei Chang,

National Taí

University Howan

University Hospital,

Taipei, Taiwan, ROC.

Accepted 20 March 1990

(Arch DisChild 1990;65:898-9)

\section{Case report}

A 6 year old boy was admitted because of paucity of interlobular bile ducts of the liver. His last admission had been as a neonate for prolonged cholestasis.

He had been born spontaneously at full term after an uneventful pregnancy and normal delivery. He was the second child in a family and there was no history of jaundice or hepatobiliary diseases in other family members.

Twenty days after birth he had progressive jaundice. At the age of 34 days, hepatomegaly, clay coloured stools, and mild jaundice were

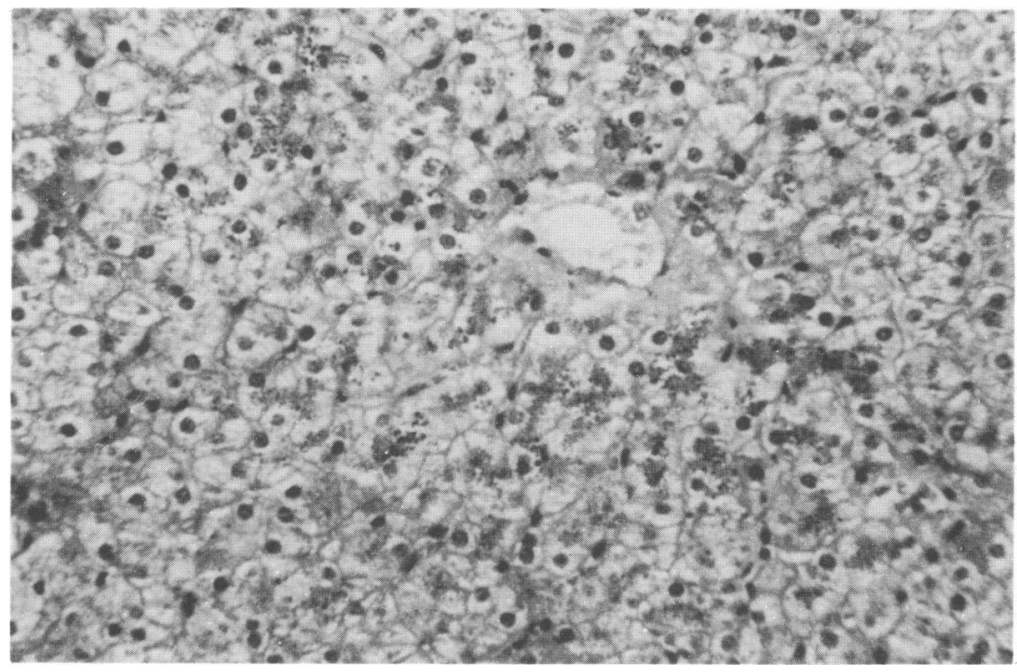

Figure 1 Liver histology at 6 years of age showing intracellular pigment granules distributed in centrilobular areas (haematoxylin and eosin stain $\times 400$ ). found. Serum bilirubin concentration (total/ conjugated) was $116 \cdot 3 / 97 \cdot 5 \mu \mathrm{mol} / \mathrm{l}$. Physical examination showed a slightly icteric baby with decreased activity. The liver was felt $2.5 \mathrm{~cm}$ below the right costal margin, and the spleen was not palpable. No heart murmur was detected.

The packed cell volume was $0 \cdot 39$, asparate aminotransferase $60 \mathrm{IU} / \mathrm{l}$, alanine aminotransferase $29 \mathrm{IU} / 1$, alkaline phosphatase $40 \cdot 1 \mathrm{IU} / 1$, and $\gamma$ glutamyltransferase $776 \mathrm{IU} / \mathrm{l}$. Investigations for prolonged infantile jaundice were performed. Abdominal sonography showed a homogenously enlarged liver with a normal sized biliary tree and portal veins; the gall bladder was visible. A ${ }^{99 m}$ Tc labelled diisopropyl iminodiacetic acid (DISIDA) scan did not visualise the radiotracer in the intestine and biliary tract, but duodenal juice analysis showed patency of the biliary tree. Investigations for toxoplasma, other viruses, rubella, cytomegalovirus, and herpes virus for congenital infection were negative. His $\alpha_{1}$ antitrypsin was 58.8 $\mu \mathrm{mol} / \mathrm{l}$. A liver biopsy was performed and paucity of interlobular bile ducts was suspected. Scarce pigment granules were found in the hepatocytes and were then interpreted as lipofuscin. (Review of the liver specimen six years later showed there were inadequate portal areas in the biopsy specimen, and the previous diagnosis was discarded.) The jaundice subsided gradually in the admission period, the total serum bilirubin concentration went down to $68.4 \mu \mathrm{mol} / \mathrm{l}$, and the stool colour became light yellow at the age of 76 days.

He had normal development and growth. Liver enzymes and bilirubin concentrations had been within normal limits for his age at the time he was followed up at 90 days. There has been no hepatosplenomegaly.

The patient had a second liver biopsy during his admission at age 6 to clarify the diagnosis of paucity of interlobular bile ducts of the liver. The liver biopsy specimens appeared dark greenish. Distinct brownish pigment granules were observed in hepatocytes in centrilobular regions and the bile ducts were adequate in number in the portal areas (fig 1). The granules were weakly positive to the periodic acid Schiff stain and negative with iron, carbol fuchsin, and Sudan stains. A sulphobromophthalein test was performed by injecting $5 \mathrm{mg} / \mathrm{kg}$ of the dye intravenously. Normal disappearance of the sulphobromophthalein was observed in the initial 45 minutes; however, another peak appeared 90 minutes after the injection (fig 2). Oral cholecystography was performed and the gall bladder was visualised with attenuated contrast medium. Analysis of serum bile acids showed 


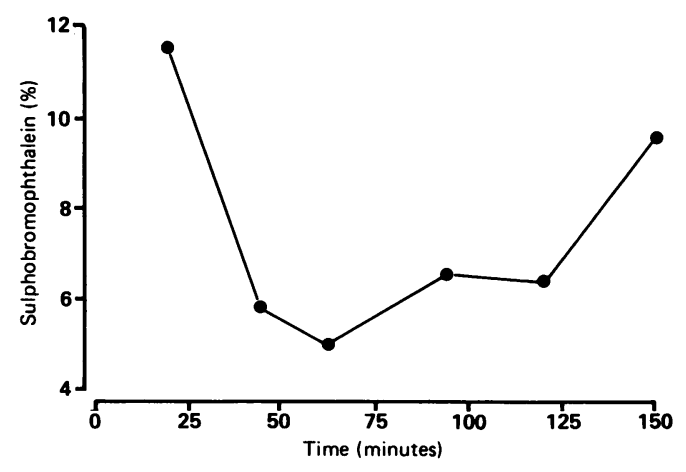

Figure 2 Sulphobromophthalein clearance curve. Retention of the dye was normal at 45 minutes after intravenous injection; another peak began to appear 90 minutes after injection.

normal pattern. The patient remained well and jaundice free after the investigation.

\section{Discussion}

The differential diagnosis of conjugated hyperbilirubinaemia in neonates is a challenge to a paediatrician. A list of differential diagnoses should include biliary atresia, neonatal hepatitis, paucity of interlobular bile ducts, and metabolic diseases. The dark greenish appearance of liver tissue, a double peaked sulphobromophthalein clearance curve, and the peculiar granules in the hepatocytes indicated the diagnosis of Dubin-Johnson syndrome in the present case.

Clay coloured stools may be found in infants with cholestasis with a patent extrahepatic biliary tree, but usually transiently. In 25 cases of intraheptic cholestasis in our series, five had clay coloured stools, of which three were transient. $^{2}$

Clinical jaundice has seldom been observed before the onset of puberty in patients with Dubin-Johnson syndrome. Although this disease was enumerated as one of the various causes of neonatal jaundice, it was not verified until 1975 when a neonate with prolonged jaundice was proved by a positive ${ }^{131} I-$ sulphobromophthalein test and quantitation of coproporphyrin isomers to have Dubin-
Johnson syndrome. ${ }^{3}$ Another similar case was reported in 1979. ${ }^{4}$ The role of Dubin-Johnson syndrome in neonatal cholestasis remains elusive, however, because the pathognomonic granules are not apparent at the newborn stage. What makes the condition more perplexing is the report that immaturity in excreting haeme metabolites-a circumstance that mimics Dubin-Johnson syndrome was present in fetuses and premature infants. ${ }^{5}$ Dubin-Johnson syndrome was referred to as the cause of jaundice in a 17 year old boy. with recurrent cholestasis since his infancy. ${ }^{6}$ Liver biopsy performed at the age of 5 weeks had failed to show the exact diagnosis because of the rarity of this disease and the lack of information about the presentation of Dubin-Johnson syndrome in early infancy. ${ }^{6}$

The visualisation of the specific pigment granules that give the peculiar dark green appearance of the liver was taken as definitive for the diagnosis of Dubin-Johnson syndrome, but the pigment may not be evident until the age of 4 years. ${ }^{7}$ Review of the liver tissue sampled at age 5 weeks from our case showed a few pigment granules, even at such an early stage of the syndrome.

Alertness about the possibility of DubinJohnson syndrome in neonatal cholestasis may make early identification of the specific pigment granules possible and help to differentiate this essentially benign disease from other conditions requiring timely treatment.

1 Berk PD. Bilirubin metabolism and the hereditary hyperbilirubinemias. In: Berk JE, ed. Gastroenterology. 4th Ed. Philadelphia: WB Saunders, 1985:2778-83.

2 Yen CM, Chang MH, Lin YH, Su CT, Hung WT. The differential diagnosis of prolonged infantille cholestasic jaundice: a prospective study. Acta Paediatrica Sinica 1984;25: 267-73.

3 Kondo T, Yagi R, Kuchiba K. Dubin-Johnson syndrome in a neonate. N Engl f Med 1975;292:1028-9.

4 Nakata F, Oyanagi K, Fujiwara M, et al. Dubin-Johnson syndrome in a neonate Eur f Pediatr 1979;132.299-301.

5 Wolkoff AW Arias IM Coproporphyrin amniotic fluid and urine from premature infants: a possible amniotic fluid and urine from premature infants:

6 Sotelo AC, Danis RK, Krafcik J, Malik M, Schwarz KB. Cholecystitis in a 17-year-old boy with recurrent jaundice since childhood. I Pediatr 1988;112:668-74.

7 Mowat AP. Hepatitis and cholestasis in infancy: intrahepatic disorders. In: Mowat AP, ed. Liver disorders in childhood. 2nd Ed. London: Butterworths, 1987:37-71. 